\title{
Lung and Parietal Hydatid Disease
}

\section{Senhaji L , Karhate M, Amara B, Elbiaze M, Benjelloun MC and Serraj M}

Department of Pneumology, University Hospital Hassan II, Fez, Morocco

${ }^{*}$ Corresponding author: Senhaji L, Department of Pneumology, University Hospital Hassan II, Road Immouzer, Fez, Morocco 30050, E-mail: issipee@yahoo.fr

Citation: Senhaji L, Karhate M, Amara B, Elbiaze M, Benjelloun MC, et al. (2016) Lung and Parietal Hydatid Disease. J Case Rep Stud 4(6): 603. doi: 10.15744/2348-9820.4.603

Received Date: May 23, 2016 Accepted Date: December 27, 2016 Published Date: December 29, 2016

\begin{abstract}
Hydatid disease, which is also known as cystic echinococcosis, is a zoonotic infection caused by the cestode tapeworm Echinococcus granulosus and rarely by Echinococcus multilocularis. In this report we describe an unusual case of a 75-year-old man who was admitted to our hospital for a mass extending from the lumbar region to the right cervical region. Computed tomography and MRI revealed a huge cervical and thoracic mass of the right chest made of multiple cystic lesions. The patient was put on medical treatment. The diagnosis, clinical features, treatment, and prevention in this case of multi-organ echinococcosis are discussed, in light of the relevant literature.
\end{abstract}

Keywords: Lung; Hydatid disease; Chest wall

\section{Case History}

We report the case of a 75years old patient having since 3years a mass extending from the lumbar region to the right cervical region with notion of hydatid vomica. On examination, we have noticed the presence of a huge mass of hard consistency occupying the posterior part of the right chest hemi field which is continuous with a right lumbar mass; with a second mass extending from the anterior and upper tier of the chest to the neck, having a soft consistency. Chest computed tomography scan (CT) confirmed the presence of a huge cervical and thoracic mass of the right chest made of multiple cystic lesions of varying sizes, extending in intrathoracic with a localized bone loss of the sixth right rib (Figure 1). Thoracic magnetic resonance imaging (MRI) showed multiple pulmonary and parietal hydatid disease made by multiple vesicles with invasion of the oval foramen (Figure 2). The indication was to put the patient under medical treatment, surgery wasn't considered given the importance and the extent of lesions.

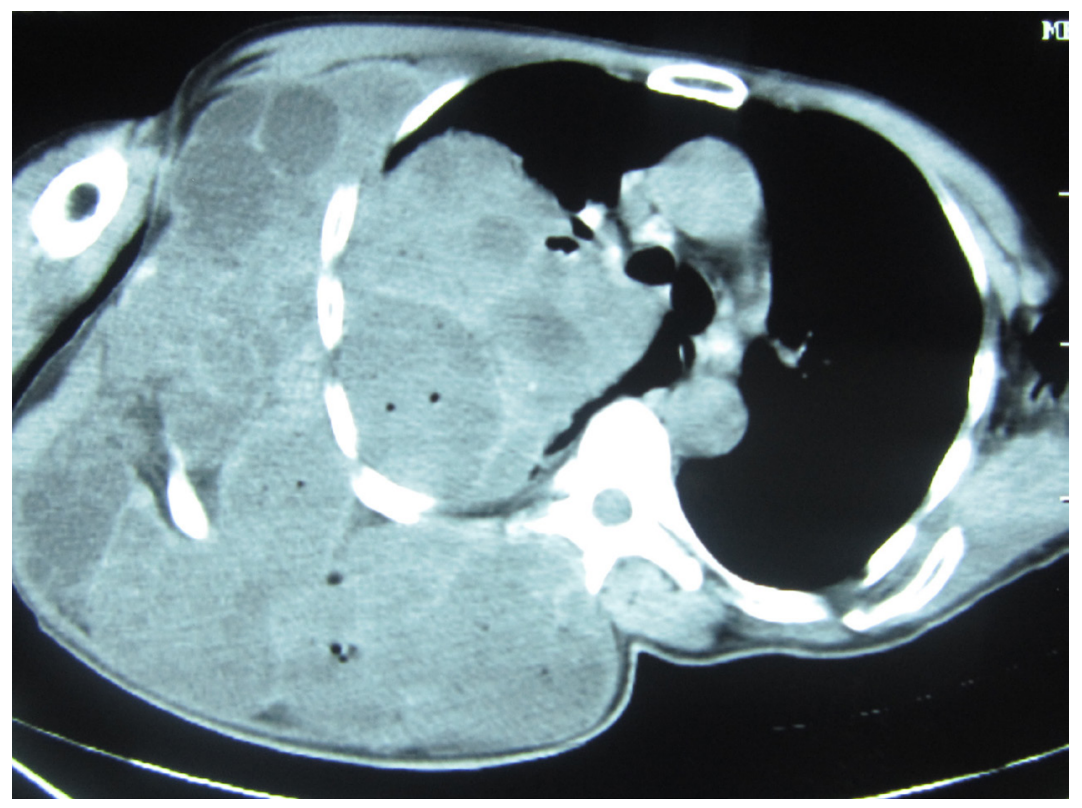

Figure 1: Chest CT in Mediastinal cut: Parietal and Lung Cystic Lesions 


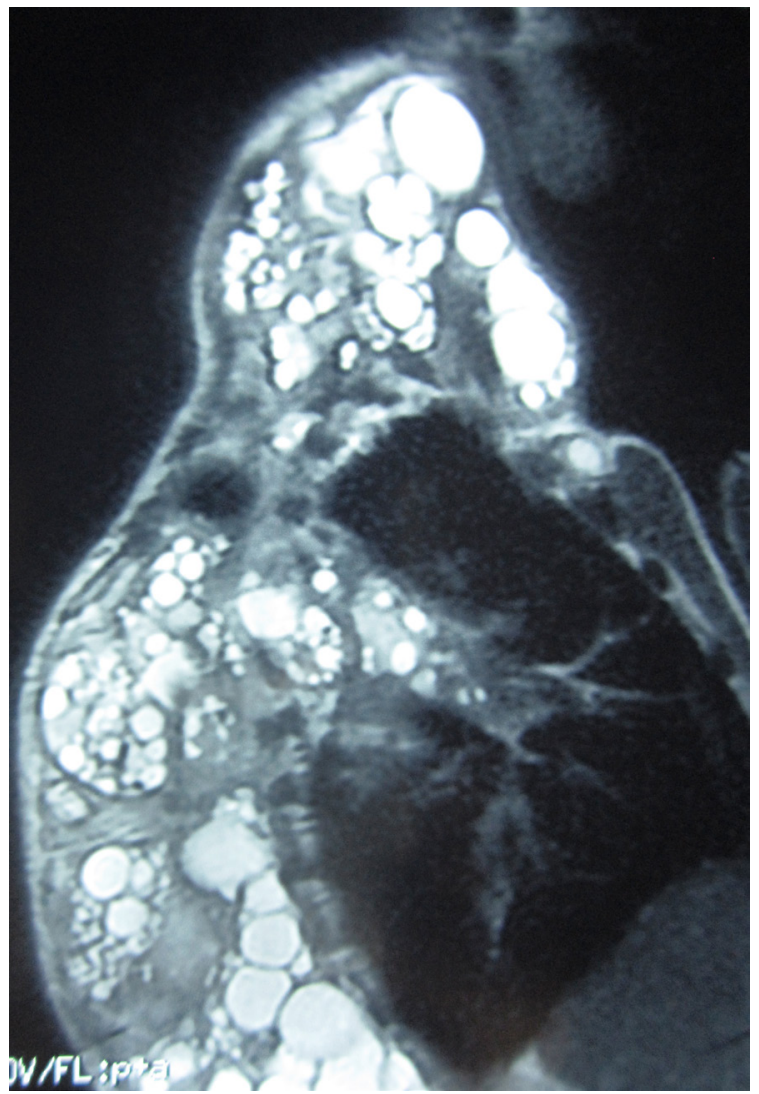

Figure 2: Chest MRI: Multiple Pulmonary and Parietal Vesicles (High Signal intensity on T2)

\section{Discussion}

Hydatidosis is a cosmopolitan anthropozoonosis due to the development, in human bodies, of the larva of echinococus granulosus. It is a public health problem plaguing the livestock country where uncontrolled logging allows contact with infected dog's viscera: Latin America, China, Oceania and the Mediterranean [1].

More than $80-90 \%$ of hydatid cysts occur in the liver, lungs, or both. Jlidi et al. reported that chest wall hydatid cysts were about 0.9-2\%. The ruptures of pulmonary hydatid cysts into the pleural space were reported to be the most common cause for pleural or chest wall hydatosis. The other pathway for extrapulmonary intrathoracic hydatid disease was known to be the invasion of liver echinococcosis to diaphragm and rupture into pleural space [2].

Diagnosis of hydatid cysts is suspected on the presence of pulmonary cysts, with a history of exposure to sheep and dogs. Radiology and serology are the principal diagnostic modality used to confirm the diagnosis. We use rarely other tests, namely a chest CT, when the radiographic appearance lends to confusion with a tumor or inflammatory disease. MRI scan shows low signal intensity on T1-weighted images and high signal intensity on T2-weighted images of the cyst $[3,4]$.

Pulmonary hydatid cysts is treated by pharmacotherapy (albendazol: $10-15 \mathrm{mg} / \mathrm{kg} / \mathrm{day}$, taken twice a day for a minimum period of 3-6 months) and/or surgery [3].

Regarding its enormous human impact, prevention should be emphasized particularly in endemic areas. Vaccination has a great potential in containing the transmission of echinococcosis in future $[1,3]$.

\section{Conclusion}

This case shines by the importance of the extension of hydatid disease and the primary role of imagery in the diagnosis confirmation.

\section{References}

1. El Biaze M (2006) Thoracic hydatid disease: new facts [Hydatidose thoracique : actualités et faits nouveaux]. Rev Mal Respir 23: 80-2.

2. Isitmangil T, Toker A, Sebit S, Erdik O, Tunc H, et al. (2003) A novel terminology and dissemination theory for a subgroup of intrathoracic extrapulmonary hydatid cysts. Med Hypotheses 61: 68-71.

3. Sarkar M, Pathania R, Jhobta A, Thakur BR, Chopra R (2016) Cystic pulmonary hydatidosis. Lung India 33: 179-91.

4. Bouchikh M, Ouadnouni Y, Smahi M, Msougar Y, Lakranbi M, et al. (2008) The multiple extra pulmonary thoracic hydatid [L'hydatidose thoracique extra pulmonaire multiple]. Rev Mal Respi 25: 1110-4. 


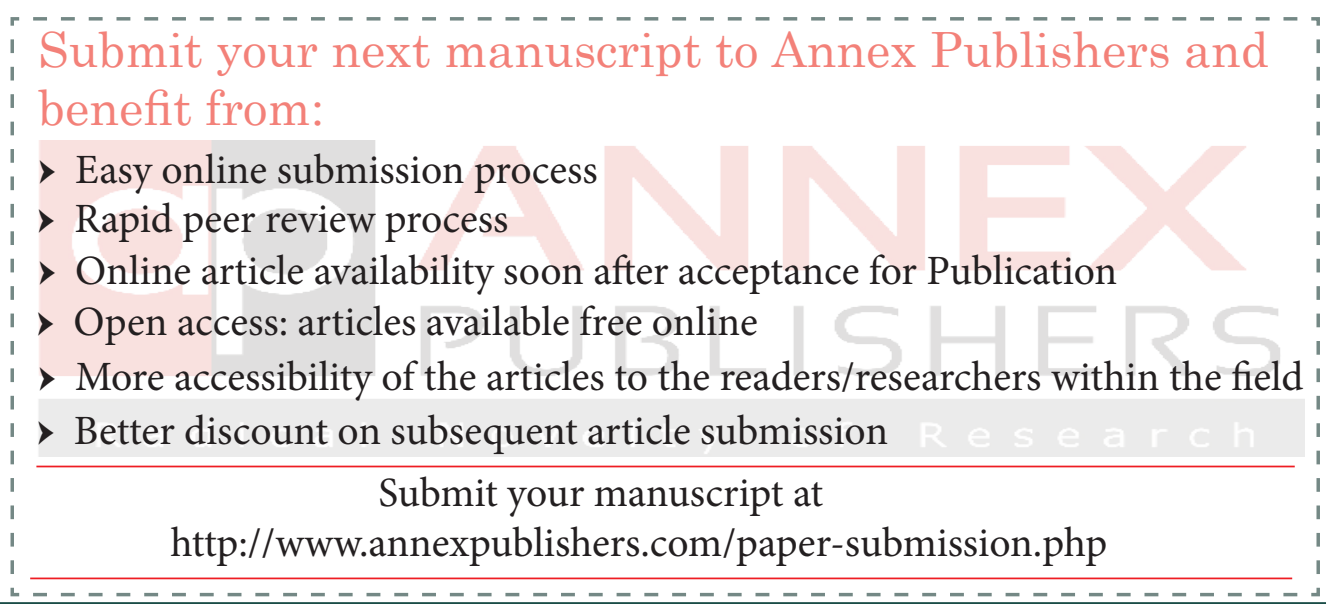

